\title{
Could clustering of comorbidities be useful for better defining the internal medicine patients' complexity?
}

\author{
Flavio Tangianu, ${ }^{1}$ Paola Gnerre, ${ }^{2}$ Fabrizio Colombo, ${ }^{3}$ Roberto Frediani, ${ }^{4}$ Giuliano Pinna, ${ }^{5}$ Franco Berti, ${ }^{6}$ \\ Giovanni Mathieu, ${ }^{7}$ Micaela La Regina, ${ }^{8}$ Francesco Orlandini, ${ }^{9}$ Antonino Mazzone, ${ }^{10}$ Clelia Canale, ${ }^{11}$ \\ Daniele Borioni, ${ }^{12}$ Roberto Nardi, ${ }^{12}$ on the behalf of the sub-group BOOK-Clinical Competence Board 2018, FADOI \\ ${ }^{1}$ Internal Medicine, S. Martino Hospital, Oristano; ${ }^{2}$ Internal Medicine, San Paolo Hospital, Savona; ${ }^{3}$ Internal Medicine, Niguarda \\ Ca' Granda Hospital, Milano; ${ }^{4}$ Internal Medicine, Maggiore Hospital, Chieri (TO); ${ }^{5}$ Internal Medicine, Cardinal Massaia \\ Hospital, Asti; 'Internal Medicine 2 Department, S. Camillo Forlanini Hospital, Roma; ${ }^{7}$ Internal Medicine, E. Agnelli Hospital, \\ Pinerolo (TO); ${ }^{8}$ Internal Medicine, Clinical Risk Manager, La Spezia; ${ }^{9}$ Health Director, ASL 4 Regione Liguria; ${ }^{10}$ Medical \\ Department, Internal Medicine, ASST Ovest-Milanese, Legnano (MI); ${ }^{11}$ Internal Medicine, S.S. Annunziata Hospital, Savigliano \\ $(\mathrm{CN}) ;{ }^{12}$ Internal Medicine, Maggiore Hospital, Bologna, Italy
}

\begin{abstract}
Internal medicine patients are mostly elderly with multiple comorbidities, usually chronic. The high prevalence of comorbidity and multimorbidity has a significant impact on both positive responses to treatment and the occurrence of adverse events. Clustering is the process of nosography grouping into meaningful associations with some index disease, so that the objects within a cluster have high similarity in comparison with one another. In the decision-making process it is imperative that, in addition to understanding the immediate clinical problems, we are able to explicit all the contextual factors that have to be taken into account for the best outcome of care. Cluster analysis could be leveraged in developing better interventions targeted to improve health outcomes in subgroups of patients.
\end{abstract}

\section{Introduction}

Multi-morbidity is like the universe. Diseases can combine infinitely, but some kinds of clusters are much more common than others ${ }^{1}$

Internal medicine patients are mostly elderly with multiple comorbidities, usually chronic. The high prevalence of comorbidity and multimorbidity has a significant impact on both positive responses to treatment and the occurrence of adverse events. The

Correspondence: Roberto Nardi, Internal Medicine, Bologna, Italy.

E-mail: nardidoc48@gmail.com

Key words: Internal medicine patients; multi/comorbidity; complexity; cluster analysis.

Conflict of interest: the authors declare no potential conflict of interest.

Received for publication: 20 October 2017.

Revision received: 13 February 2018.

Accepted for publication: 17 April 2018.

This work is licensed under a Creative Commons Attribution NonCommercial 4.0 License (CC BY-NC 4.0).

CCopyright F. Tangianu et al., 2018

Licensee PAGEPress, Italy

Italian Journal of Medicine 2018; 12:137-144

doi:10.4081/itjm.2018.940 large majority of oldest old subjects have multimorbidity, such as hypertension, diabetes mellitus, dyslipidemia, ischemic cardiomyopathy, heart failure, stroke, chronic obstructive pulmonary disease, atrial fibrillation, peripheral arterial disease, Parkinson's disease, cancer, dementia, anemia, chronic kidney disease, visual impairment and deafness. ${ }^{2}$ The current focusing on single diseases should be replaced with a holistic view and approach to the patterns of comorbidity and multimorbidity in the real clinical care world (Table 1).3-5

\section{Older adults with multimorbidity are heterogeneous: the complexity of measuring clinical complexity}

Older adults with multimorbidity are heterogeneous in terms of illness severity, functional status, prognosis, personal priorities, and risk of adverse events. ${ }^{6}$ Multimorbidity generally refers to the presence of multiple clinical conditions, but a multitude of patient-level factors independent of specific comorbid conditions may complicate care and affect outcomes. An important dimension of multimorbidity is the comorbidity interrelatedness, i.e. the degree to which conditions interact to affect clinical management and outcome. ${ }^{7}$ By definition, for research on multimorbidity no index disease is used, whereas for comorbidity research an index disease is obligatory. ${ }^{8}$ According to these views, we stated that 
Comorbidity does not reflect complexity in internal medicine patients. ${ }^{9}$ Many indices are now available for estimating a multimorbidity score by weighting a range of diseases (e.g., Charlson Comorbidity Index ${ }^{10}$ or Cumulative Illness Rating Scale).$^{11}$ Other applied multimorbidity measures are the Chronic Disease Score, ${ }^{12}$ the RxRisk Model, ${ }^{13}$ or the Duke Severity of Illness Checklist. ${ }^{14}$ Safford et al. proposed a conceptual approach to complex patients involving interactions between biological, socioeconomic, cultural, environmental, and behavioral forces as health determinants. ${ }^{15}$ Thus, the issue of better defining the complexity, its prognostic implications and to provide suitable assessment tools is compelling. The complexity of measuring clinical complexity was the title of an editorial published on the Annals of Internal Medicine in 2011. ${ }^{16}$ Indeed the concept of complexity in Internal Medicine lacks a precise definition. ${ }^{17} \mathrm{~A}$ Veterans Affairs working group defined complexity as requiring challenging clinical decisionmaking and care processes that are not routine or standard. ${ }^{18}$ Complexity is the quality of being intricate and compound. It refers to the degree of complication of a system or of a system component, determined by such factors as the number and intricacy of interfaces, the number and intricacy of conditional branches, the degree of nesting, and the types of data structures. ${ }^{19}$ According to these meanings, complexity in a patient involves the intricate entanglement of two or more systems (e.g., body diseases, family socioeconomic

Table 1. What does comorbidity mean and which are the related implications?

Comorbidity means that more than one disease or condition is present in the same person at the same time.

Conditions described as comorbidities are often chronic or long-term conditions. Other ways to name comorbid conditions are coexisting or co-occurring conditions and sometimes also multimorbidity or multiple chronic conditions.

- Comorbidity: additional presence of a disease in relation to a specific clinically dominant index disease in an individual;

- Multimorbidity: presence of multiple diseases in an individual;

- Clusters of diseases: two or more co-occurring specific chronic diseases;

- Burden of morbidity: the overall impact of different diseases in an individual taking into account their severity.

And some other definitions: ${ }^{3}$

- Trans-syndromal comorbidity: represents the coexistence of two or more syndromes pathogenetically related to each other;

- Trans-nosological comorbidity: denotes the coexistence of two or more nosological units pathogenetically related to each other.

\section{Classification}

- Counts (a merely count of number/sum of diseases)

- Concordant or Discordant*:5

- Concordant comorbidities:

- referred to diseases as parts of the same pathophysiologic risk profile and more likely to share the same management and are more likely to be the focus of the same disease management plan (for example, the triad of hypertension, diabetes and coronary artery disease)

- sharing common etiological factors

- if improvements in one risk area is likely to reduce risks elsewhere.

- Discordant comorbidities:

- referred to diseases that are not directly related in either pathogenesis or management and do not share an underlying predisposing factor, e.g. type 2 diabetes mellitus and asthma or diabetes and prostate cancer);

- on average we develop one new long-term condition (LCT) every 5 years from the age of 55

- treatment for one LTC may have no impact on other comorbidities

- in some cases, treatment options conflict e.g. the use of L-DOPA for Parkinsonism with history of psychosis

Evidence to describe multimorbidity is often incomplete

- Pressure for simplicity in data collection

- Time consuming tools

- Specificity/sensibility of assessment tools not optimal

\section{Significance}

- Clinical aspects, such as: interpreting symptoms, symptomatic versus asymptomatic chronic comorbidities/finding underlying/not overt/iceberg diseases

- Inappropriate performance/outcome metrics

- Modified risks of mortality

- Risk of poor mobility and health status

- Burden on resource utilization, on caregivers

- Multidimensional assessment need

- Need to know context to inform patient-centered care

Comorbidities and co-treatment may be critical in optimizing or worsening outcomes

- Comorbidities are never considered as a confounding factor in the evaluation of the outcomes in most of the clinical trials

- Decreased relevance of evidence-based medicine and clinical guidelines, with some implications in clinical accountability

- Judicious use and appropriate selection of medication therapies by the competent Internal Medicine doctor has to ensure safety in managing comorbidities, preventing exacerbations, and minimizing poly-pharmacy adverse drug reactions and drug-drug related interactions

Modified from Alexander, $2016 .{ }^{4}$ *The nature and direction of the observed associations not always are fully explained by the concordant-discordant model. ${ }^{5}$ 
status, therapies) and how a disease may influence multiple systems. ${ }^{20}$ In complexity, the interaction of multiple different factors in the same patient (social, medical, family, therapy, etc.) and its consequences have to be assessed in a multidimensional approach. Patient complexity cannot adequately be captured in measures focusing only on comorbid conditions, ${ }^{21}$ but considering all potential interactions between several factors, such as between illnesses, multiple medications and treatments, multiple providers and tension between therapeutic goals. Several factors may contribute to the final quality of care.

\section{The clustering disease tool}

There has been very little research to date exploring the prevalence of particular combinations or clusters of chronic conditions. Almost all studies examining specific comorbidities do so from the perspective of a specific index disease rather than examining all co-occurring chronic conditions. ${ }^{22,23}$ Most clinical guidelines address single diseases, often missing treatment of patients with multimorbidity and co-occurrence of multiple (chronic) diseases within one person. Clustering is the process of nosography grouping into meaningful associations with some index disease, so that the objects within a cluster have high similarity in comparison to one another, but are dissimilar to objects in other clusters. ${ }^{24}$ The disease clusters approach could serve as a first priority setting towards the development of new multimorbidity guidelines, with the most frequently occurring diseases and combinations. ${ }^{25}$ In elderly patients some associations are useful in identifying groups of those at risk of in-hospital adverse clinical events and death, according to disease clustering ${ }^{26}$ (Table 2).

\section{An example: the chronic heart failure}

A paradigmatic example of some potential interactions between several medical conditions is specifically referred to chronic heart failure, one of the most prevalent disease in Internal Medicine wards. ${ }^{27}$ This process has to consider all pharmacologic and managing options in a multidimensional assessment context $\mathrm{t}^{28}$ (Figure 1).

\section{The comorbidome concept}

Comorbidities influence not only the severity of the symptoms and the quality of life of individual patients, but also their prognosis, as risk of hospitalization and death. Adding comorbidity tools in the assessment of some index disease, for instance chronic obstructive pulmonary disease (COPD), is very useful for significantly improved outcome prediction. ${ }^{29-32}$ Comorbidities are frequent in COPD and some of them could negatively influence survival. The comorbidome concepts was introduced as a useful representation of the prevalence and impact of comorbidities in hospitalized COPD patients: it is a graphic representation of the prevalence and strength of association to mortality constructed on the bases of a multivariate analysis of all the comorbidities that increase mortality. ${ }^{33,34}$ Thus we have to consider that management of the complexity of multimorbidity could be useful in achieving a better quality of life and prognosis for patients. ${ }^{35-37}$

\section{Frailty as a further factor for complexity}

Frailty is a further factor that contributes to increasing complexity, with poor outcomes. In the REPOSI registry, enrolling 2841 patients aged 65 or older admitted to internal medicine and geriatric wards, four clusters were identified: i) the healthiest; ii) those with multimorbidity; iii) the functionally independent women with osteoporosis and arthritis; and iv) the functionally dependent oldest old patients with cognitive impairment. A significantly higher inhospital mortality was found in Cluster II [odds ratio $(\mathrm{OR})=2.27,95 \%$ confidence interval $(\mathrm{CI})=1.15-4.46]$ and Cluster IV $(\mathrm{OR}=5.15,95 \% \mathrm{CI}=2.58-10.26)$ and a higher 3-month mortality in Cluster II (OR=1.66, 95\%

Table 2. Associations between pair of diseases and inhospital outcome.

\begin{tabular}{|c|c|c|}
\hline Pair of diseases & (for age, $\mathrm{g}$ & $\begin{array}{l}\text { Adjusted } \\
\text { gender and education) } \\
\text { OR (95\% CI) }\end{array}$ \\
\hline Hypertension & Diabetes & $1.7(1.3-2.2)$ \\
\hline & CVD & $2.0(1.4-2.7)$ \\
\hline & Dyslipidemia & $4.5(2.9-6.8)$ \\
\hline Chronic heart failure & $\mathrm{AF}$ & $4.6(3.1-7.0)$ \\
\hline & COPD & $2.2(1.5-3.5)$ \\
\hline & CRF & $2.4(1.5-3.9)$ \\
\hline Coronary heart disease & COPD & $1.7(1.2-2.2)$ \\
\hline Diabetes & CHD & $2.5(1.9-3.3)$ \\
\hline & CVD & $1.7(1.2-2.3)$ \\
\hline & Dyslipidemia & $2.0(1.4-2.9)$ \\
\hline & CRF & $2.3(1.6-3.3)$ \\
\hline Liver cirrhosis & Anemia & $2.9(1.7-4.2)$ \\
\hline & Malignancy & $2.9(1.8-4.7)$ \\
\hline Thyroid dysfunction & $\mathrm{AF}$ & $2.5(1.6-3.8)$ \\
\hline Chronic renal failure & Anemia & $2.6(1.7-4.1)$ \\
\hline Gastric diseases & Intestinal diseases & $3.1(1.9-5.0)$ \\
\hline
\end{tabular}

OR, odds ratio; $\mathrm{CI}$, confidence interval; $\mathrm{CVD}$, cerebrovascular disease; $\mathrm{AF}$, atrial fibrillation; COPD, chronic obstructive pulmonary disease; CHD coronary heart disease; $\mathrm{CRF}$, chronic renal failure. 


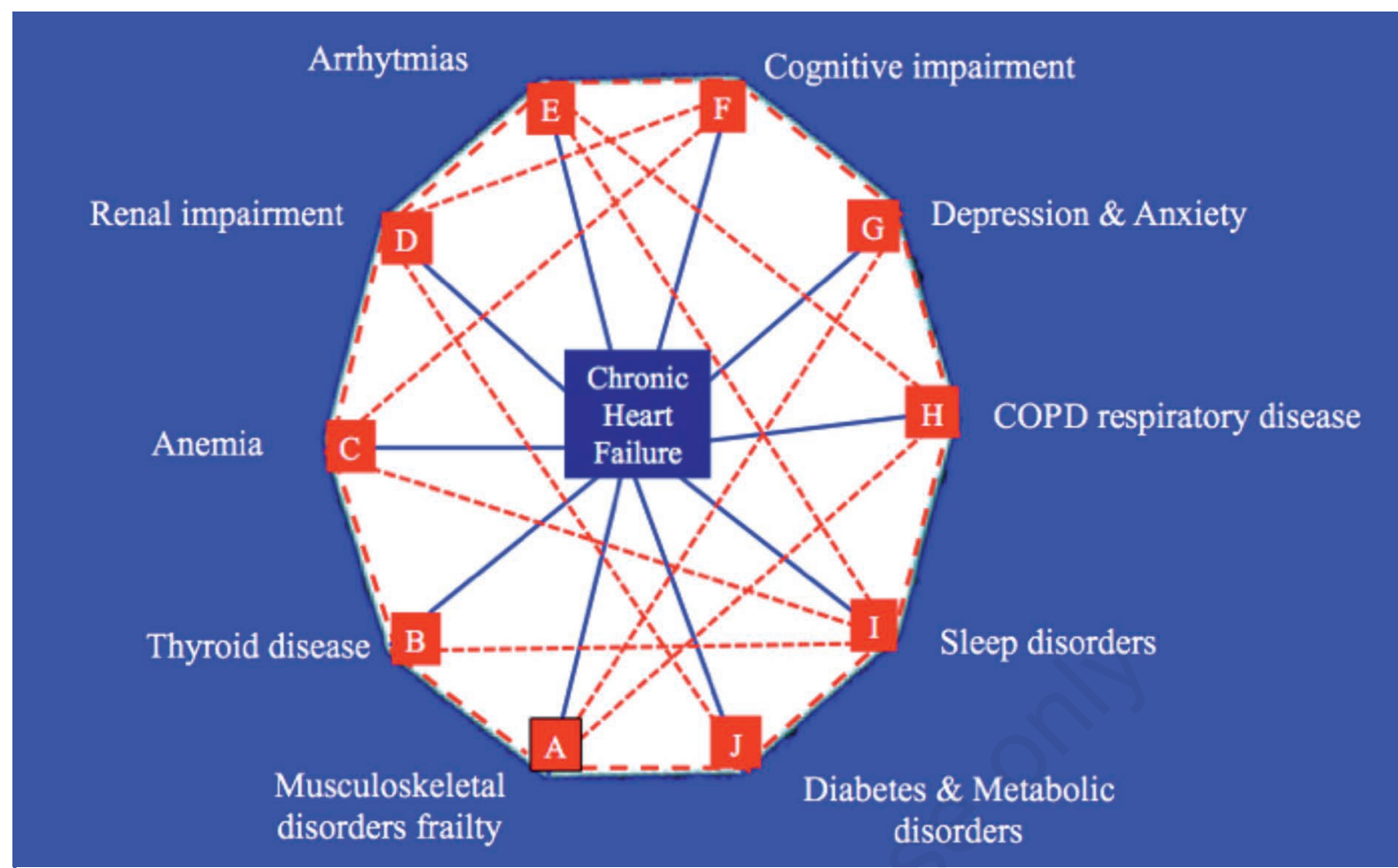

Note: Ten most common conditions were identified as several combinations. There are multiple points of interaction between these factors that inevitably lead to high levels of patient complexity, with subsequent prognostic implications and premature mortality without therapeutic intervention. The blue lines indicate the direct and concordant relationship between CHF and single comorbidities; the dotted red lines indicate the relations between CHF and some discordant co-morbidities.

\section{Figure legend:}

\section{A: Musculoskeletal system diseases, frailty}

Muscle wasting reduces exercise capacity and muscle strength, and a reduced skeletal muscle mass is greatly associated with advanced chronic HF.

In patients with HF, the presence of frailty is associated with significantly worse outcomes. The lack of physiologic reserve in frail patients allows acute stressors to cause rapid functional deterioration and debility. In addition to a two-fold increase in mortality risk, frail HF patients experience greater rates of hospitalization, endure longer lengths of stay, have increased risk of rehospitalization.

\section{B: Thyroid disorders}

Both hyperthyroidism and hypothyroidism can be primary or contributory causes of HF.

\section{C: Anemia}

There are potential beneficial effects of anemia treatment with erythropoietic agents on exercise capacity and quality of life in CHF patients. Further studies are needed to determine the optimal threshold for initiation of treatment and target hemoglobin during therapy.

\section{D: Acute/chronic kidney dysfunction}

A loss of glomerular filtration rate, as in acute kidney injury (AKI) or chronic kidney disease (CKD), independently predicts mortality and accelerates the overall progression of cardiovascular disease and HF.

The coexistence of heart failure and renal dysfunction constitutes the cardiorenal syndrome which is increasingly recognized as a marker of poor prognosis.

\section{E: Atrial and ventricular arrhythmias}

Both atrial and ventricular arrhythmias are common in patients with heart failure (HF) and cardiomyopathy, regardless of underlying etiology. They can cause symptoms, morbidity (such as stroke due to embolization with atrial fibrillation) and may be responsible for sudden cardiac death (SCD).

\section{F: Cognitive dysfunction/dementia}

It may be important to carry out a screening for cognitive dysfunction as it may influence HF patients' prognosis and their ability to perform self-care, $e$. $g$. make lifestyle changes, adhere to medical treatment and monitor, evaluate and treat symptoms of deterioration.

\section{G: Anxiety/depression}

The prevalence of depression and anxiety is high in both chronic obstructive pulmonary disease (8-80\% depression; 6-74\% anxiety) and chronic heart failure (10-60\% depression; $11-45 \%$ anxiety).

\section{H: COPD and pulmonary diseases}

Chronic obstructive pulmonary disease (COPD) and heart failure are different conditions. But both can make you short of breath when you do something physical, like exercise, climbing stairs, or walking for a long distance.

\section{I: Sleep disorders}

Sleep-disordered breathing, short sleep time, and low sleep quality are frequently reported by patients with heart failure (HF). Sleep-disordered breathing, which includes obstructive sleep apnea (OSA) and central sleep apnea (CSA), is common in patients with HF.

\section{J: Diabetes mellitus, metabolic syndrome and dyslipidemia}

Diabetes not only increases the risk of HF, but also accelerates its occurrence. The prognosis for patients with heart failure is worse in those with diabetes than in those without diabetes.

Metabolic syndrome [insulin resistance, hypertension (high blood pressure), cholesterol abnormalities, and augmented risk of clotting] increases the risk of heart failure burden being an important risk factor.

Figure 1. Chronic heart failure and some of its potential interactions with and between several conditions. 
$\mathrm{CI}=1.13-2.44)$ and Cluster IV (OR=1.86, 95\% $\mathrm{CI}=1.15-3.00)$ than in Cluster I. Some quantified most prevalent medical conditions, as cluster analysis according to main anchoring conditions in the elderly, are reported in Table 3. In this series, frailty of the elderly is mostly associated with mental health conditions, diabetes, obesity, stroke, cardiac disease, kidney disease, skin ulcers and dementia. ${ }^{38}$

\section{In a complex patient the clinical decision-making is very complex}

In complex patients, health professionals are required to make decisions with multiple foci, such as diagnosis, intervention, interaction and evaluation, in several setting of care and in dynamic contexts, with different skills between professionals decision makers, with multiple variables involved, often in situations of uncertainty, reduced relevance of clinical guidelines and lack of evidence. Patterns from overall multimorbidity analyses have potential implications for clinical decision-making and patient management, such as drug-disease, disease-disease, and drug-drug interactions, and in clinical practice and research. ${ }^{39}$ Socioeconomic factors may contribute to the outcome of chronic diseases and quality of life ${ }^{40}$ (Figure 2).

\section{Conclusions}

In order to redesign our health care systems to more effectively care for complex patients, we need a better handle on exactly who they are. ${ }^{21}$

Simply counting the number of comorbid conditions does not really capture whether a patient is complex..$^{9,17,21}$ In patients with multimorbidity, there is a co-occurrence of diseases beyond chance, which clinicians have to take into account in their daily practice. ${ }^{41}$ In complex patients a multidimensional approach in identifying and addressing the best care is needed ${ }^{6}$ (Table 4).

Different multimorbidity patterns share some diagnosis groups, influence each other and overlap in a large part of the population. In recognizing the full complexity of multimorbidity we might improve our

Table 3. Subgroups of elderly complex patients identified through cluster analysis.

\begin{tabular}{|c|c|}
\hline Anchoring conditions & Most prevalent medical conditions in cluster $(\%)$ \\
\hline Chronic pain with mental conditions & $\begin{array}{c}\text { Chronic pain (99.8) } \\
\text { Mental health conditions (69.2) } \\
\text { Obesity (47.2) }\end{array}$ \\
\hline Diabetes with obesity and mental health conditions & $\begin{array}{c}\text { Diabetes }(100) \\
\text { Obesity (86) } \\
\text { Mental health conditions (44) }\end{array}$ \\
\hline Kidney disease with diabetes and obesity & $\begin{array}{c}\text { Kidney disease }(99.9) \\
\text { Diabetes }(51.2) \\
\text { Obesity }(50.9)\end{array}$ \\
\hline Frailty related in the elderly & $\begin{array}{c}\text { Mental health conditions (45.4) } \\
\text { Diabetes (39.7) } \\
\text { Obesity (37.7) } \\
\text { Stroke }(35.2) \\
\text { Cardiac disease }(30.7) \\
\text { Kidney disease }(26.7) \\
\text { Skin ulcers }(26.4) \\
\text { Dementia }(25.8)\end{array}$ \\
\hline Cardiac disease and obesity & $\begin{array}{c}\text { Cardiac disease (100) } \\
\text { Obesity }(54.2) \\
\text { Diabetes }(39.4)\end{array}$ \\
\hline COPD with obesity and mental health conditions & $\begin{array}{c}\text { COPD (100) } \\
\text { Obesity }(60.4) \\
\text { Mental health conditions }(55.4)\end{array}$ \\
\hline Gastrointestinal bleeding with obesity and mental health conditions & $\begin{array}{l}\text { Gastrointestinal bleeding (100) } \\
\text { Obesity (42.1) } \\
\text { Mental health disorders (34.9) }\end{array}$ \\
\hline Abdominal and orthopedic surgeries with obesity & $\begin{array}{l}\text { Abdominal surgery (66.7) } \\
\text { Obesity (60.8) } \\
\text { Orthopedic surgery (48.0) }\end{array}$ \\
\hline Cancer with obesity and mental health conditions & $\begin{array}{c}\text { Cancer (100) } \\
\text { Obesity (47.7) } \\
\text { Mental health disorders (33.9) }\end{array}$ \\
\hline
\end{tabular}

COPD, chronic obstructive pulmonary disease. 
ability to predict needs and achieve possible benefits for elderly patients who suffer from multimorbidity. ${ }^{42}$ Knowledge of the pathophysiologic interactions between comorbidities increases the understanding of their development and contributes to strategies for prevention or improved treatment. ${ }^{43}$ To study the multimorbidity pattern can be useful to improve clinical management of each specific subgroup of patients showing a particular multimorbidity pattern. ${ }^{44}$ Higher prevalence in older adults of specific combinations of diseases could help us in the development of clinical practice guidelines (CPGs) that account for the simultaneous presence of multiple chronic conditions. In order to assure CPGs more patient centered rather than disease driven, guideline developers should include information on elderly patients with comorbidities and their interrelatedness. ${ }^{45}$ Studying disease combinations could serve as a first priority setting towards the development of multimorbidity guidelines ${ }^{46}$ starting with the diseases with the highest observed prevalence rates and those with potential interacting treatment plans. ${ }^{47}$ In the decision-making process it is imperative that, in addition to understanding the immediate clinical problems, we are able to explicit all the contextual factors that have to be taken into account for the best outcome of care. Cluster clinical analysis methods are appropriate to detect subgroups of entities, but many problems are associated with

Table 4. Strategies to address comorbidity among Internal Medicine patients.

- Improving the evidence-based care to make treatment and management decision for those with comorbidity, by implementing further clinical trials in the real world including complex patients

- Improving the measurement of comorbidity

- Improving integration and coordination of care

- Preventing the occurrence of new comorbidities and limiting exacerbations of existing conditions

- Developing better tools to be used by clinicians for the prognosis

- Facilitating skill development for clinicians

- Building further research collaborations

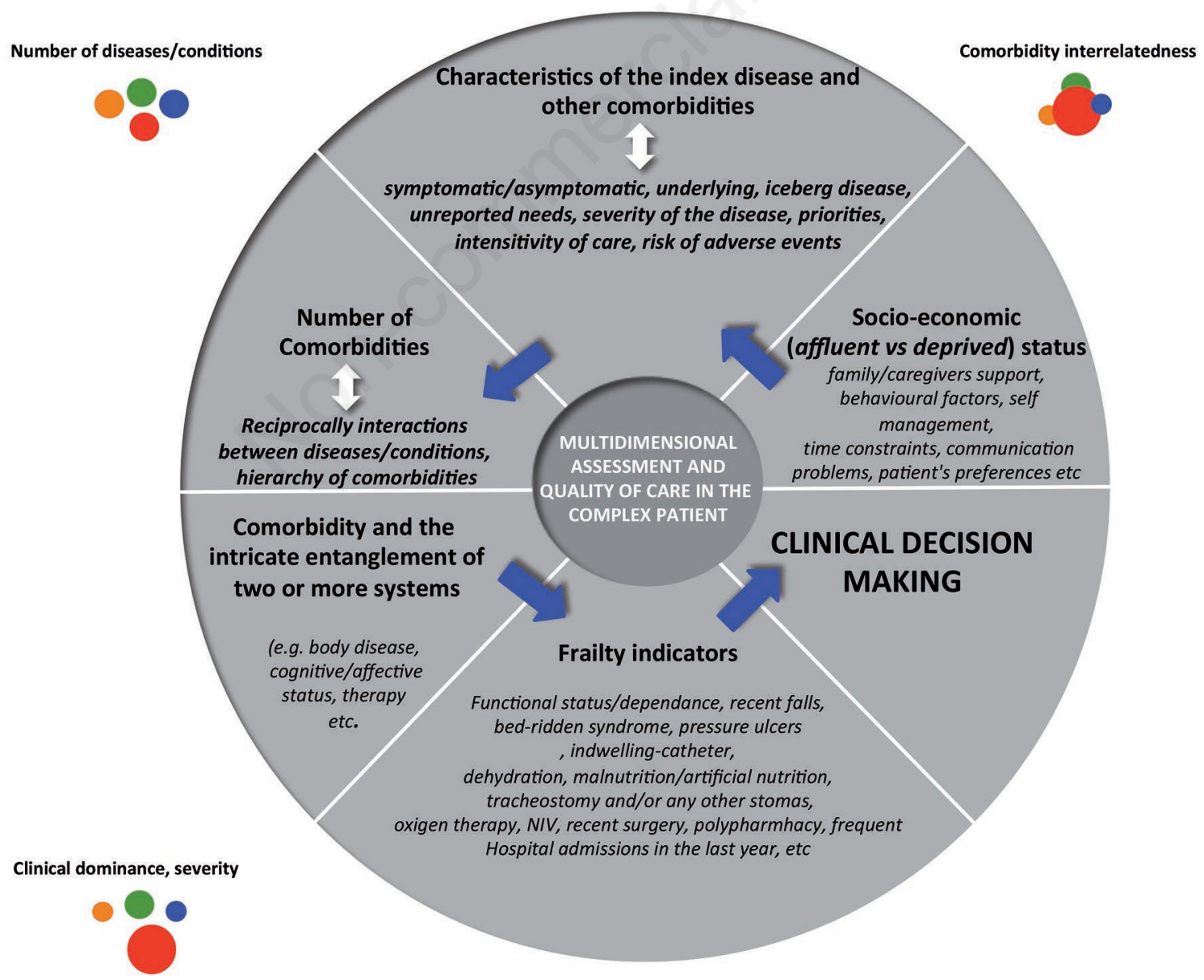

Figure 2. In a complex patient the clinical decision-making is very difficult. 
clustering techniques, e.g., the scaling of variables, the choice of clustering method, or the testing of the validity of the clusters found. ${ }^{48}$ Cluster clinical analysis could be leveraged in developing better interventions targeted to improve health outcomes in subgroups of patients whose optimal care management is less well defined..$^{49}$ Further studies and research are needed in this area. ${ }^{50}$

\section{References}

1. Minerva. Clustering of comorbidities and other stories. BMJ 2015;351:h4273.

2. Formica F, Ferrer A, Sanz H, et al. Patterns of comorbidity and multimorbidity in the oldest old: The Octabaix study. EJIM 2013;24:40-4.

3. Jakovljević M, Ostojić L. Comorbidity and multimorbidity in medicine today: challenges and opportunities for bringing separated branches of medicine closer to each other. Med Acad Mostarien 2013;1:18-28.

4. Alexander KP. Managing multiple comorbidities in the elderly; 2016. Available from: https://dcri.org/wpcontent/uploads/2016/10/Alexander-Multimorbidity.pdf

5. Ricci-Cabello I, Stevens S, Kontopantelis E, et al. Impact of the prevalence of concordant and discordant conditions on the quality of diabetes care in family practices in England. Ann Fam Med 2015;13:514-22.

6. Boyd CM, McNabney MK, Brandt N, et al. AGS expert panel on the care of older adults with multimorbidity, patient-centered care for older adults with multiple chronic conditions: a stepwise approach from the American Geriatrics Society, American Geriatrics Society Expert Panel on the Care of Older Adults with Multimorbidity. Am Geriatr Soc 2012;60:1957-68.

7. Zulman DM, Asch SM, Martins SB, et al. Quality of care for patients with multiple chronic conditions: the role of comorbidity interrelatedness. J Gen Intern Med 2013;29:529-37.

8. de Groot V, Beckerman H, Lankhorst GJ, Bouter LM. How to measure comorbidity: a critical review of available methods. J Clin Epidemiol 2003;56:221-9.

9. Nardi R, Scanelli G, Corrao S, et al. Co-morbidity does not reflect complexity in internal medicine patients. Eur J Intern Med 2007;18:359-68.

10. Charlson ME, Pompei P, Ales KL, MacKenzie CR. A new method of classifying prognostic comorbidity in longitudinal studies: development and validation. J Chronic Dis 1987;40:373-83.

11. Linn BS, Linn MW, Gurel L. Cumulative illness rating scale. J Am Geriatr Soc 1968;16:622-6.

12. Von Korff M, Wagner EH, Saunders K. A chronic disease score from automated pharmacy data. J Clin Epidemiol 1992;45:197-203.

13. Fishman PA, Goodman MJ, Hornbrook MC, et al. Risk adjustment using automated ambulatory pharmacy data: the RxRisk model. Med Care 2003;41:84-99.

14. Parkerson GR Jr, Broadhead WE, Tse CK. The Duke Severity of Illness Checklist (DUSOI) for measurement of severity and comorbidity. J Clin Epidemiol 1993;46: 379-93.

15. Safford MM, Allison JJ, Kiefe CI. Patient complexity: more than comorbidity. The vector model of complexity. J Gen Intern Med 2007;22:382-90.

16. Turne BJ, Cuttle L. The complexity of measuring clinical complexity. Ann Intern Med 2011;155:851-2.

17. Nardi R, Berti F, Greco A, et al. Complexity in hospital internal medicine departments: what are we talking about? Ital J Med 2013;7:142-55.

18. Weiss KB. Managing complexity in chronic care: an overview of the VA state-of-the-art (SOTA) conference. J Gen Intern Med 2007;22:374-8.

19. Wilson T, Holt T, Greenlagh T. Complexity and clinical care. Br Med J 2001;323:685-8.

20. Tucker PS, Scanlan AT, Dalbo VJ. Chronic kidney disease influences multiple systems: describing the relationship between oxidative stress, inflammation, kidney damage, and concomitant disease. Oxidat Med Cell Longev 2015;2015:1-8.

21. Grant RW, Ashburner JM, Hong CC, et al. Defining patient complexity from the primary care physician's perspective-a cohort study. Ann Intern Med 2011;155: 797-804.

22. Gijsen R, Hoeymans N, Schellevis FG, et al. Causes and consequences of comorbidity: a review. J Clin Epidemiol 2001;54:661-74.

23. Vogeli C, Shields AE, Lee TA, et al. Multiple chronic conditions: prevalence, health consequences, and implications for quality, care management, and costs. J Gen Intern Med 2007;22:391-5.

24. Buchin K, Buchin M, van Kreveld M, et al. Clusters in aggregated health data. Available from: https://pdfs. semanticscholar.org/0491/9bc12242090b16b9ef971d12 87b11d4ae251.pdf

25. Sinnige J, Braspenning J, Schellevis F, et al. The prevalence of disease clusters in older adults with multiple chronic diseases - a systematic literature review. PLoS One 2013;8:e79641.

26. Marengoni A, Bonometti F, Nobili A, et al. In-hospital death and adverse clinical events in elderly patients according to disease clustering: the REPOSI study. Rejuven Res 2010;13:469-77.

27. Stewart S, Riegel B, Boyd C, et al. Establishing a pragmatic framework to optimise health outcomes in heart failure and multimorbidity (ARISE-HF): a multidisciplinary position statement. Int $\mathrm{J}$ Cardiol 2016;212:1-10.

28. DeJongh B, Birkeland K, Brenner M. Managing comorbidities in patients with chronic heart failure, first do no harm. Am J Cardiovasc Drugs 2015;15:171-84.

29. Agustì A, Vestbo J. Current controversies and future perspectives in chronic obstructive pulmonary disease. Am J Respir Crit Care Med 2011;184:507-13.

30. Fabbri LM, Luppi F, Beghé B, Rabe KF. Complex chronic comorbidities of COPD. Eur Respir J 2008; 31:204-12.

31. Fabbri LM, Beghé B, Agusti A. COPD and the Solar System - Introducing the chronic obstructive pulmonary disease comorbidome. Am J Respir Critical Care Med 2012;186:117-9.

32. de Torres JP, Casanova C, Marin JM, et al. Prognostic evaluation of COPD patients: GOLD 2011 versus BODE and the COPD comorbidity index COTE. Thorax 2014;69:799-804.

33. Divo M, Cote C, de Torres JP, et al. The BODE 
Collaborative Group. Comorbidities and risk of mortality in patients with chronic obstructive pulmonary disease. Am J Respir Crit Care Med 2012;186:155-61.

34. Almagro P, Cabrera FJ, Diez-Manglano J, et al. Comorbidome and short-term prognosis in hospitalised COPD patients: the ESMI study. Eur Respir J 2015;46: 850-3.

35. Kessler R, Casan-Clara P, Koehler D, et al. COMET: a multicomponent home-based disease-management programme versus routine care in severe COPD. Eur Respir J 2018;51:1701612.

36. Rose L, Istanboulian L, Carriere L, et al. Program of integrated care for patients with chronic obstructive pulmonary disease and multiple comorbidities (PIC COPD+): a randomised controlled trial. Eur Respir J 2018;51:1701567.

37. Vanfleteren LEGW, Ullman A, Fabbri LM. Time for a longer and better life for patients with COPD. Eur Respir J 2017;0:1702569.

38. Marcucci M, Franchi C, Nobili A, et al. Defining aging phenotypes and related outcomes: clues to recognize frailty in hospitalized older patients. J Gerontol A Biol Sci Med Sci 2017;72:395-402.

39. Goodman RA, Ling SM, Briss PA, et al. Multimorbidity patterns in the United States: implications for research and clinical practice. J Gerontol A Biol Sci Med Sci 2016;71:215-20.

40. Tüzün H, Aycan S, İlhan MN. Impact of comorbidity and socioeconomic status on quality of life in patients with chronic diseases who attend primary health care centres. Cent Eur J Public Health 2015;23:188-94.

41. Marengoni A, Rizzuto D, Wang HW, et al. Patterns of chronic multimorbidity in the elderly population. JAGS 2009;57:225-30.

42. Schäfer I, von Leitner E-C, Schön G, et al.
Multimorbidity patterns in the elderly: a new approach of disease clustering identifies complex interrelations between chronic conditions. PLoS One 2010;5:e15941.

43. Vanfleteren Lowie EGW, Spruit MA, Groenen M, et al. Clusters of comorbidities based on validated objective measurements and systemic inflammation in patients with chronic obstructive pulmonary disease. Am J Respir Crit Care Med 2013;187:728-35.

44. Guisado-Clavero M, Roso-Llorach A, López-Jimenez T, et al. Multimorbidity patterns in the elderly: a prospective cohort study with cluster analysis. BMC Geriatrics 2018;18:16.

45. Mutasingwa DR, Ge H, Upshur REG. How applicable are clinical practice guidelines to elderly patients with comorbidities? Can Fam Physician 2011;57:e253-260.

46. Shekelle P, Woolf S, Grimshaw JM, et al. Developing clinical practice guidelines: reviewing, reporting, and publishing guidelines; updating guidelines; and the emerging issues of enhancing guideline implementability and accounting for comorbid conditions in guideline development. Implement Sci 2012;7:62.

47. Sinnige J, Braspenning J, Schellevis F, et al. The prevalence of disease clusters in older adults with multiple chronic diseases - a systematic literature review. PLoS One 2013;8:e79641.

48. Vogt W, Nagel D. Cluster analysis in diagnosis. Clin Chem 1992;38:182-98.

49. Newcomer SR, Steiner JF, Bayliss EA. Identifying subgroups of complex patients with cluster analysis. Am J Manag Care 2011;17:e324-32.

50. Marengoni A, Fratiglioni L. Disease clusters in older adults: rationale and need for investigation. J Am Geriatr Soc 2011;59:2395-6. 